\title{
MANIFESTATIONS OF CEREBRAL DYSFUNCTION IN INFANCY AND THEIR ASSOCIATION WITH TOXAEMIA AND ANTEPARTUM HAEMORRHAGE
}

\section{A COHORT STUDY}

\author{
C. J. ROBERTS \\ Department of Social and Occupational Medicine, Welsh National School of Medicine, Heath Park, Cardiff
}

The delayed consequences of fetal and neonatal pathology are much more difficult to measure than their immediate influence on mortality. Those who die in late infancy or early childhood and, potentially, those whose congenital handicap is an anatomical one visible at, or soon after, birth are countable. However, many other congenital disorders (for example, cerebral palsy and deafness) cannot be diagnosed in early infancy.

The supposition that toxaemia or antepartum haemorrhage may be either major or contributory causes of neurological and behavioural disorders in childhood derives principally from the knowledge that perinatal mortality is high in both those maternal conditions. As yet, however, the mechanism of death is not fully understood (Buck, 1967; Baird and Thomson, 1969), although the presence of prematurity may well be a factor in some cases. Among infants surviving a toxaemic pregnancy there is certainly thought to be a possibility of residual damage, particularly to the central nervous system. The studies of Lilienfeld and Pasamanick (1954) and of Lilienfeld, Pasamanick, and Rogers (1955) in Baltimore and New York State, based upon careful retrospective comparisons of brain-damaged and normal children, implicate a number of obstetric complications-in particular, toxaemia and antepartum haemorrhage (Pasamanick and Knobloch, 1959). It is not yet certain, however, whether either of these complications exerts its effect in the absence of prematurity or of the other complications of pregnancy or labour with which they are frequently associated.

Existing evidence in favour of an association between childhood neuropsychiatric disorder and toxaemia or antepartum haemorrhage derives almost entirely from case history studies. In such studies 'brain-damaged' children are categorized by their similarity in respect of several simultaneously presenting manifestations of illness, and then a history is taken of their frequency of exposure to toxaemia and antepartum haemorrhage. A comparable group of children without the disease is studied in a similar way. However, setting limits of a disease entity such as brain damage on a manifestational basis is a highly complex and, in part, an intuitive procedure, and from the outset considerable confusion has resulted from the use of this term. In particular, there is little doubt that brain damage is much more likely to be diagnosed among infants who are found to have a history of an abnormal pregnancy or birth than among those who have not (Birch, 1964), thus condemning the findings of retrospective (case history) studies.

The study reported in this paper has attempted to avoid this dilemma by following up a cohort of infants, who experienced toxaemia or antepartum haemorrhage during pregnancy, until they were 12 months old, at which time a detailed developmental and neurological examination was undertaken together with a similar examination of an equal number of matched controls. The examination was undertaken 'blind', i.e., the identity of the subjects (cases and controls) was not known to the examiner.

\section{Materials AND Methods}

Since 1963 the obstetric history of every child born in Cardiff has been fully documented as part of the on-going Cardiff Birth Survey. Thus infants whose mothers experienced toxaemia and/or third-trimester bleeding in this group were easily identified.

Between 1 January 1966 and 31 January 1967, 231 live-born infants in the South-East Health Division of Glamorgan were known to have been born to mothers who had experienced toxaemia and/or antepartum haemorrhage during the related pregnancy; of them, two-thirds were born in one of two specialist maternity units in Cardiff. There remained, however, certain infants whose mothers had experienced bleeding or toxaemia but were born 
either at home or at a general practitioner maternity unit. These subjects were identified from the birth notification cards completed by the attending midwife at the time of or shortly after the birth of the child. Because antepartum haemorrhage/toxaemia may be under-reported in domiciliary confinements, the writer visited each midwife in the study area to explain the purpose of the survey, and he also maintained close liaison with them during the period of the study. Consequently, he believes that the domiciliary birth notifications referred to in this project achieved a reasonable level of accuracy.

Controls were selected from files of all reported births occurring in the study area. The matching procedure was as follows: all births occurring on the same day as the index case were removed from the file and then matched in order for parity, maternal age, place of birth, sex, and, where possible, social class. If a satisfactory control born on the same day could not be found, a sequence of one day forward, one day back, two days forward, two days back, and so on, was adopted.

One hundred and ninety-three subjects $(84 \%$ of the original cohort) were given a detailed developmental and neurological examination on, or as near to, their first birthday as possible, together with an equal number of matched controls. Over the same period there were 2,507 live births and 41 still births in the study area.

The level of development was ascertained by the Gesell Developmental Test (Gesell and Amatruda, 1941) which consists of items divided into five subscales: gross motor, fine motor, adaptive, language, and personal social. The developmental age scores are a function of the number of items passed at a particular age, and the test is designed to yield both aggregate and subscale developmental quotients. The presence of neurological disorder was determined by the use of a battery of observations covering muscle tone, reflex activity, neuromotor patterns, and special sensory function (Gesell and Amatruda, 1941; Knobloch and Pasamanick, 1962; Roberts, 1968). Approximately 300 items of information were required to complete the project questionnaire, of which 200 were behavioural observations and the remainder historical data. It was evident from the outset that many difficulties would beset an examiner who attempted to write up his own examination schedule. The sponsors of this project, therefore, generously agreed to finance a research assistant to act as a recorder and to accompany the examiner on home visits. Thus, historical data were recorded as mothers answered the questions posed by the examiner, and behavioural observations were called out by the examiner to the recorder who entered them in the appropriate section of the schedule. The recorder also informed the examiner when be- 3 havioural observations had been omitted, and $\stackrel{\mathbb{Q}}{Q}$ checked on the completeness of the recording throughout the test procedure.

\section{RESULTS}

The incidence of toxaemia and antepartum $\frac{\overline{\bar{\rho}}}{5}$ haemorrhage in the total birth population for the $\stackrel{\mathbb{Q}}{2}$ area over the period of the study was 9.2 per $100 \%$ births. Of the 193 mothers who experienced toxaemia $\overrightarrow{-}$ and/or antepartum haemorrhage, $66 \%$ experienced $\stackrel{\circ}{-}$ toxaemia alone, $29 \%$ antepartum haemorrhage $\vec{\omega}$ alone, and $5 \%$ a combination of both. A $\chi^{2}$ analysis? of observed and expected incidence rates of toxaemia $\stackrel{\bar{\Omega}}{\odot}$ and antepartum haemorrhage occurring together in the same pregnancy gave $P<0.001$, suggesting that 0 . their association is not likely to be one of chance. $\omega$

There was no evidence that the delivery experience $\vec{\omega}$ of the cases differed significantly from that of the 0 controls. Twelve per cent of cases weighed less than $5 \frac{1}{2} \mathrm{lb}$ at birth compared with $6 \%$ of controls $\left(\mathrm{P}_{\supset}\right.$ $<0.003$ ), and $11.5 \%$ of cases were gestationally immature (i.e., $<38$ weeks) compared with $4.1 \%$ of $\frac{c}{c}$ controls $(\mathbf{P}<0.008)$. Although there were twice as many low birth weight babies among the cases the difference is believed to be due to an excess of. gestationally immature infants in the case group afo will be explored in a subsequent paper.

The mean aggregate and subscale developmental quotients among the cases and the controls are shown in Table I; each case subscale score is lower $\stackrel{\square}{\varrho}$ than the equivalent score in the controls, but all are $\overrightarrow{\vec{O}}$ within twice the standard error of the mean, and 3 thus the difference is not statistically significant. A correlation matrix analysis of the interrelation? between the aggregate and subscale developmental $\frac{1}{\circ}$ quotients of both cases and controls was undertaken $\stackrel{?}{?}$ in order to compare internal consistency: none of $\dot{0}$ the paired comparisons of the 30 correlation coefficients calculated (15 in the case group and $15 \%$

TABLE I

DISTRIBUTION OF MEANS AND STANDARD DEVIATIONS $D$ OF AGGREGATE AND SUBSCALB DEVELOPMIENTAL O

\begin{tabular}{|c|c|c|c|c|c|}
\hline \multirow{3}{*}{$\begin{array}{l}\text { Developmental } \\
\text { Subgroup }\end{array}$} & \multicolumn{5}{|c|}{ Developmental Quotients } \\
\hline & \multicolumn{2}{|c|}{ Cases } & \multicolumn{2}{|c|}{ Controls } & \multirow[b]{2}{*}{$t$ Test } \\
\hline & Mean & S.D. & Mean & S.D. & \\
\hline Aggregate & 90.04 & 10.9 & $91 \cdot 4$ & 9.9 & ns \\
\hline $\begin{array}{l}\text { Gross motor } \\
\text { Fine motor } \\
\text { Adaptive } \\
\text { Language } \\
\text { Personal social }\end{array}$ & $\begin{array}{l}96 \cdot 3 \\
94 \cdot 1 \\
87 \cdot 2 \\
85 \cdot 4 \\
87 \cdot 1\end{array}$ & $\begin{array}{l}15.5 \\
10.0 \\
13.9 \\
13.9 \\
13.4\end{array}$ & $\begin{array}{l}97 \cdot 5 \\
95 \cdot 5 \\
90 \cdot 1 \\
85 \cdot 5 \\
88 \cdot 5\end{array}$ & $\begin{array}{l}15 \cdot 4 \\
9 \cdot 3 \\
12 \cdot 1 \\
13 \cdot 4 \\
13 \cdot 3\end{array}$ & $\begin{array}{l}\text { ns } \\
\text { ns } \\
\text { ns } \\
\text { ns } \\
\text { ns }\end{array}$ \\
\hline
\end{tabular}


TABLE II

DISTRIBUTION IN SAMPLE OF INFANTS WITH NEUROLOGICAL ABNORMALITY BY AGGREGATE DEVELOPMENTAL QUOTIENT

\begin{tabular}{|c|c|c|}
\hline $\begin{array}{l}\text { Aggregate Developmental } \\
\text { Quotient Graded by Standard } \\
\text { Deviation from Mean }\end{array}$ & Cases & Controls \\
\hline \multirow[t]{2}{*}{$\begin{array}{ll}\text { Within } 1 & \text { S.D. from mean } \\
\text { Within } & \text { S.D. from mean } \\
\text { Within } 1-2 & \text { S.D. from mean } \\
\text { More than } 2 & \text { S.D. from mean }\end{array}$} & $\begin{array}{l}2 \\
1 \\
4 \\
3\end{array}$ & $\begin{array}{l}1 \\
0 \\
0 \\
1\end{array}$ \\
\hline & $10(5 \cdot 2 \%)$ & $2(1 \%)$ \\
\hline
\end{tabular}

*Difference significant at $P<0.02$

in the control) differed by a statistically significant amount.

The distribution of infants with abnormal neuromotor patterns in the sample by aggregate developmental score is shown in Table II. The frequency of neurological abnormality was increased five-fold among the cases compared with the controls $(\mathrm{P}<0.02)$.

\section{Discussion}

The simplest criterion of cause and effect is that the suspected agent and the disease should always be found together, with its converse, that if the agent is absent, so is the disease. It is usual also to require that the incidence of the specific disease should vary almost in step with the intensity of the supposed aetiological factor. The evidence relating neurological disorder to toxaemia and antepartum haemorrhage in no way begins to fulfil either of these criteria: thus the simple logical framework of a direct causal association is inappropriate. In practice, paediatric neurological disorders are probably the net results of an interacting causative complex of genetic and environmental factors. The assessment of separate influences, or the interaction between them which determines disease (or significant deviation from the norm), requires a more sophisticated conceptual model.

One stage in testing the hypothesis of cause and effect would be to compare the frequency of obstetric complications in population groups similar in all but one respect (namely, the suspected outcome). This technique of retrospective enquiry has been used by Pasamanick, Rogers, and Lilienfeld (1956), Crothers and Paine (1959), and Ingram (1964) to demonstrate an increased frequency of complications of pregnancy and birth among children with defined mental disorders. However, reference has already been made to the complication that clinicians are more likely to diagnose brain damage in infants who have a known history of complications of pregnancy and birth, and this invalidates many of the findings of retrospective enquiries.
This problem can be mitigated by prospective surveys which follow the experience of a whole cohort of infants who have been independently classified in some way before the period of observation begins. Nevertheless such enquiries will have certain imperfections. For example, there is no way of foretelling who, or how many, of the presumed healthy population surveyed will develop neurological damage. For most serious disorders the attack rate is so low that large numbers must be surveyed to obtain enough cases to ensure stable and accurate incidence rates in the contrasted subgroups of the survey population. A follow-up of a disease with an expectancy of $1 \%$ would require the inclusion of at least 3,000 individuals in each of the contrasted groups to be reasonably certain of detecting that one incidence rate was twice the other. Taking the approximate frequencies of severe subnormality to be $0.04 \%$, of cerebral palsy $0.01 \%$, of congenital deafness $0.01 \%$, and of minimal cerebral damage $0.02 \%$, prospective studies of disorders such as these would require sample sizes so large that only relatively simple investigations, such as questionnaires administered by lay observers, could be employed.

The particular question of the relationship between obstetric complications and fetal neurological disorder therefore raises two difficult problems:

(1) The qualitative nature of the mental disorder will usually require a complex and specialized investigative procedure for its accurate determination for survey purposes; and, when the condition sought for has an expectancy of only $0.01 \%$, it is essential that no cases are missed. Both these considerations demand examination of the sample by a trained specialist.

(2) The only way of making sure that the assessment is administered to a sufficiently large sample to ensure enough cases to determine accurate incidence rates is to employ a large number of observers. When the information collected is qualitative, or needs a subjective interpretation by the observer, the problem of observer variation is magnified. This need conflicts directly with (1) above.

In view of these difficulties it is improbable that knowledge of the influence of obstetric complications on paediatric neurological disorder can be furthered by a prospective study of whole birth populations. One further possibility remains, namely to increase the likely yield of neurological disorder by selecting a group (or groups) of infants who, from the experience of previous surveys, are thought likely to have a higher expectancy of disorders, and to match them with randomly selected 'controls' from the same section of the population. This is the 
method used in this study.

When what are generally considered to be highrisk categories were chosen it was somewhat surprising to find that the yield of neurological disorder among cases still remained very low. This observation must almost certainly dismiss a causal association between toxaemia and antepartum haemorrhage and fetal neurological damage. However, the possibility that toxaemia and antepartum haemorrhage may play an intermediate role in a causative chain of events still warrants consideration. If toxaemia and antepartum haemorrhage are harmful only to fetuses already 'predisposed' to suffer damage, the frequency of their association with fetal damage would be limited to those occasions on which the 'predisposing' factor is also present. This hypothesis might explain the low attack rate of neurological disorder recorded among cases in the present study. Some support for this suggestion derives from the findings presented in Table III, which shows the relative risk of neurological abnormality combined with an aggregate developmental quotient of more than one standard deviation below the mean among cases by certain categories of obstetric experience. Although the numbers on which the risk rates have been calculated are small and only the risk rate difference between all cases and all controls is statistically significant, there is nevertheless a suggestion that the associated risk increases as the pregnancy and birth become more complicated. Whether each complication completes a link in the causal chain complex, or whether one complication, in particular, is a vital primary predisposing factor, is unknown. Further studies of the neurological outcome of fetal cohorts categorized by their experience of different groups of multiple obstetric complications (e.g., as in Table III) might help to answer this problem.
Finally, an important gap in our knowledge concerns the role of gestational immaturity in infant 3 morbidity. It is generally accepted as the most im-? portant factor in perinatal mortality and is the $\overrightarrow{\vec{F}}$ essential lethal factor in toxaemia and antepartum $\stackrel{\rho}{?}$ haemorrhage. It may, however, also be a vital link in the association between toxaemia and antepartum $\frac{\overline{\bar{O}}}{\overline{\bar{N}}}$ haemorrhage and infant neurological disorder.

\section{Summary}

The results of a study of the manifestations of $\overrightarrow{0}$ cerebral dysfunction in a cohort of 1-year-old infants who experienced toxaemia and/or ante- $\vec{\omega}$ partum haemorrhage during the associated preg $-\frac{\infty}{\infty}$ nancy are presented in this paper.

In order to equate the conflicting demands posed N by, on the one hand, the low attack rate of paediatric $\omega$ mental disorder, which thus requires large study $\vec{\omega}$ populations in order to ensure stable incidence rates,, and, on the other, the problems of observer variation, a two-tier approach was used with one observer $\overrightarrow{-}$ only, in which the likely yield of neurological disorder was increased by selecting a group of infants who seemed likely (from previous study) to show a raised expectation of neurological disorde्e $\overrightarrow{.0}$ The findings of this group were then compared wi those from a randomly selected matched contrồl group.

Between 1 January 1966 and 31 January 1967, the mothers of 231 liveborn infants in the South-。 East Health Division of Glamorganshire experienced $\stackrel{\AA}{\propto}$ toxaemia antepartum haemorrhage during their $\overrightarrow{\vec{B}}$ related pregnancies. One hundred and ninety-three $\frac{}{3}$ infants $(84 \%)$ were given a detailed developmental and neurological examination on or as near to their: first birthday as possible together with an equal

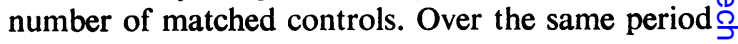

TABLE III

RELATIVE RISK OF A COMBINATION OF NEUROLOGICAL ABNORMALITY AND AN AGGREGATE DEVELOPMENTAL QUOTIENT GREATER THAN 1 S.D. BELOW THE MEAN AT 1 YEAR, BY OBSTETRIC COMPLICATION EXPERIENCED

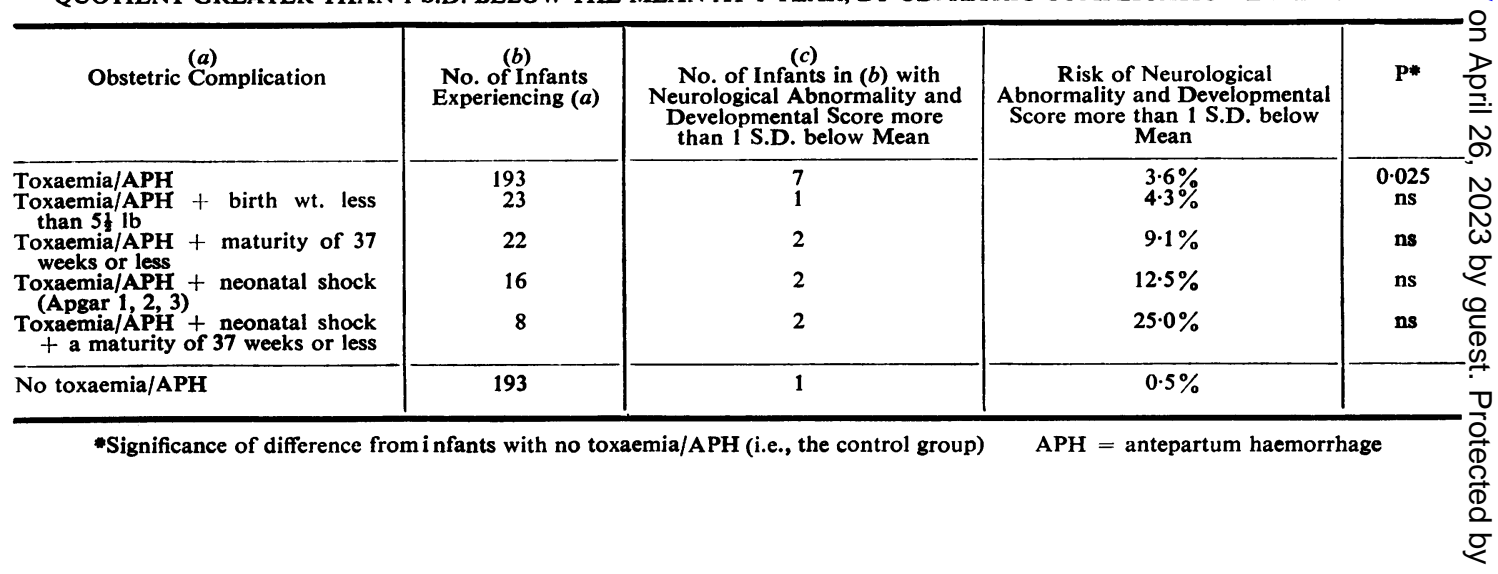


there were 2,507 live births and 41 stillbirths within the study area.

The mean aggregate and subscale developmental quotients of infants whose mothers experienced toxaemia/antepartum haemorrhage were lower than those of matched controls. The difference is not statistically significant. The frequency of neurological abnormality was increased five-fold among cases compared with controls $(P<0.02)$. However, the increased frequency of neurological abnormality and developmental delay among cases did not appear to be an expression of a general influence of toxaemia/antepartum haemorrhage throughout the whole sample. There was a suggestion that the relative risk of infant neurological disorder following toxaemia/antepartum haemorrhage was related, in some way, to the presence of certain other obstetric complications-in particular, gestational immaturity.

The possible role of toxaemia/antepartum haemorrhage in the causal complex of paediatric neurological disorder is briefly discussed.

The research was sponsored by a generous grant from the Association for the Aid of Crippled Children, New York.

I am indebted to Dr. W. E. Thomas, Medical Officer of Health for Glamorgan, for allowing me both access to the medical records and the opportunity to liaise with the health visitor staff working in the area where the research was undertaken.

\section{REFERENCES}

BAIRD, D., and Thomson, A. M. (1969). The survey perinatal deaths reclassified by special clinico-pathological assessment. In Perinatal Problems, edited by N. R. Butler and E. D. Alberman, p. 200, Livingstone, Edinburgh.
BIRCH, H. G. (1964). Brain Damage in Children-the Biological and Social Aspects, edited by H. G. Birch. Association for the Aid of Crippled Children, New York.

Buck, C. W. (1967). Prenatal and perinatal causes of early death and defect. In Preventive Medicine, edited by D. W. Clark, and B. MacMahon, p. 143. Little, Brown, Boston.

Crothers, B., and Paine, R. S. (1959). The Natural History of Cerebral Palsy. Harvard University Press, Cambridge, Massachusetts.

Gesell, A., and Amatruda, C. (1941). Developmental Diagnosis. Hoeber, New York.

Ingram, T. T. S. (1964).'Paediatric Aspects of Cerebral Palsy. Livingstone, Edinburgh.

Knobloch, H., and Pasamanick, B. (1962). The developmental behavioral approach to the neurologic examination in infancy. Child Develop., 33, 181.

Lilienfeld, A. M., and Pasamanick, B. (1954). Associa tion of maternal and fetal factors with the developmen of epilepsy. J. Amer. med. Ass., 155, 719.

_- - ROGERS, M. (1955). Relationship between pregnancy experience and the development of certain neuropsychiatric disorders in childhood. Amer. $J$. publ. Hlth, 45, 637.

Pasamanick, B., and KnOBloch, H. (1959). Complications of pregnancy and neuropsychiatric disorder. J. Obstet. Gynaec. Brit. Emp., 66, 753.

-, Rogers, M. E., and LiLIenfeld, A. M. (1956). Pregnancy experience and the development of behavior disorder in children."Amer. J. Psychiat., 112, 613.

RoBerTS, C. J. (1968). Screening for defective hearing in infancy. Publ. Hlth (Lond.), 82, 173. 